\title{
THE MEASUREMENT OF INNOVATION FOR MANAGEMENT, RESEARCH AND POLICY
}

\section{Cristian Gangaliuc}

Faculty of Information Studies, Slovenia

E-mail: cristian.gangaliuc@fis.unm.si

Abstract: This paper is a literature review regarding the known practices of measuring innovation, for policy, research or management purposes. Article is deliberating on the importance of known and most notable methodologies, such as innovation survey, interviews, case studies and mixed research. The following methodologies are presented with regard to their strong and weak points, to perform an objective evaluation and exemplification. Alongside methodologies, paper concentrates on the practices of innovation measurement, such as approaches taken by the OECD and EU assessments, presenting the possible angles that can be conceptualized during conceptualization and innovation measurement. The article ends with the presentation of the concept of Management of Innovation, that is a growing paradigm that emphasizes the ability of an actor to innovate rather than its development outcomes. Following the line of presented methodologies, approaches and considerations, conclusions outline that innovation is becoming more and more a social phenomenon, rather than a purely technical one. That presents an opportunity to build practices of including innovation into the semiotic and economic dialogue of national and supranational bodies, and not limit the policy of innovation to regional or national strategies.

Key-words: innovation, innovation measurement, management of innovation, Cultural Political Economy, Europe 2020, strategy and policy

\section{Introduction}

Economic realities (as a sum of total economic factors) are too complex and unstructured to be the subjects of analysis and measurement. In the process of reduction of complex nature of empirical phenomena, societies resorted to the usage of economic imaginary. As semiotic constructs of specific styles, genres, discourses, etc. economic imaginaries represent only particular elements of economic reality that are presented in a fixed individual, organizational and institutional manner (Jessop and Oosterlynck 2008). In 
the modern economic, sociologic and technological fields, one of the most prominent imaginaries is the concept of innovation. From the early XXth century, since Schumpeter elaborated his statement regarding the essence of competition, delivering a model of innovation's occurrence/functioning mechanism was a continuous interest for the scientific community and policymakers. In the academic environment, the concept had been notably discussed since works of Porter (1990), Granovetter (1985) and other scholars that conceptualized spatial and network reliance of the innovation phenomenon.

Establishing the link between the competitive advantage and innovativeness raised the necessity for practical understanding of the principles and components of innovation. Academia focused its efforts to comprehend the phenomena and begun to research the mechanisms of "wielding this force". Through the continuous process of variation, selection and retention of public dialogue (Jessop and Oosterlynck 2008), the topic gained the attention of entrepreneurs, public, private and co-operative research teams, as it promises the opportunity for development. However, the task was proven to be difficult, with various setbacks, including a lack of consent on the definition of innovation, path-dependent nature of the innovative phenomenon and multivariate character of the concepts involved. The debates are engulfing various characteristics, including the distinction of innovation decisions (e.g. what to consider a routine upgrade, incremental improvement or radical change, etc.), and, surely, the methods to assess these innovative variations (Kleinknecht and Bain 1993; Oslo Manual 2005).

Implementing new or improving existing products and/or production steps shows more potential for economic growth, than mere increasing capital investment and quantity of inputs (Rosenberg 2004). Thus, policymakers submit to promoting and establishing innovation-friendly economic environments. Supranational institutions, such as Organization of Economic Cooperation and Development (OECD) and European Union (EU), are engaged in practices of capitalizing innovation potentials, investing not only in the processes that ensure innovation but also in its consistent research and monitoring (Oslo Manual 2005). European Union has stated a focal interest in the concept of development and improvement, addressed through the "Europe 2020 A strategy for smart, sustainable and inclusive growth" and had done multiple empirical steps to fulfil it. As a result, EU shows commitment to the idea of innovation by financing and promoting the innovative discourse through Horizon 2020, Erasmus plus or Interreg Programmes.

Economic performers of micro and macro levels can notably increase their developmental capacities thorough accepting the innovative paradigm. 
Economic reality, in truth, requires companies and regions to be innovative, in their quest for better performance and higher profit. However, the practice of Japan, Korea and other regions (e.g. Porter 1990; Sohn and Kenney 2007) shows that the models and principles of innovation can, and should be, improved not only naturally (through economic competition) but also through public and private efforts. As an example, the discourse promoted by EU in the area of Knowledge-Based Economy (Europe 2020, 2010; Jessop 2008) places innovation as a key factor for development. This is why, description, understanding and explanation of an economic imaginary (that can be (re)developed through the ways of measuring it) has an important role in establishing and anchoring semiotic concepts into the attitudinal and behavioural patterns on individual, organizational, institutional, including regional, national and supranational levels.

Elaborating a successful economic imaginary is the best way to achieve a successful action and reaction for the intended purposes (Jessop 2008; Jessop and Oosterlynck 2008). For these imaginaries to grow and routinize they shall be promoted on different levels and become a basic dialogue not only for institutional visions but also to be retained as self-evident necessity on social levels (Makarovič et al. 2014). That implies that understanding and measuring innovation can influence an enterprise's innovative performance (Edison et al. 2013; Saunila 2016). Considered a no-cost or low-cost effort, measuring and monitoring offers the potential for establishing a model of innovative process (Erkens et al. 2013). Performed alongside other fundamental business measurements, it is a notably good experience for enterprises (Saunila 2017). Having a system to quantify innovation helps supervise the activity leading to value creation, and further establish a company's strategy or routine/culture of innovation. Moreover, it assists management with decision-making and support activities, helping identify the developmental attributes (Edison et al. 2013; Saunila 2016, 2017).

In the context of regional and national levels, analysing the innovative characteristics is of utmost interest for the administrative bodies, political actors and other policy-influencing stakeholders. Moreover, National (and Regional) Innovation Systems (Jessop 2008) are common economic imaginary among OECD and EU members. Eurostat and OECD bodies measure innovative performance annually, establishing continuous comparative monitoring (Oslo Manual 2005). Regional Innovation Scoreboard would resemble a notable effort of having a friendly and open display of innovation across the EU. Regardless of the complications to have different national economic priorities, contextual differences and strategic visions, that would jeopardize the validity of any singular tools for innovation assessment 
(Makarovič et al. 2014), Regional Innovation Scoreboard is considered relatively adequate for monitoring innovative performance for comparative purposes. These practices are performed to promote and correspondingly adjust the innovative policies, and serves as continuous revision and variation of innovation dialogue, leading to its practical (re)selection and continuous (re)integration in the strategic visions. For the theories emphasizing that innovations are achieved through actor-interactions, networking and supportive inputs from environment (e.g. Porter 1990; Cook 1992), macroeconomic indicators of innovativeness are opening new perspectives for the applicability and analysis of data.

As theories on innovation, in the fields of economy, sociology, regional development and technological engineering indicate, innovation occurs on various levels and most often requires diverse conditions. The multitude of theories and perspectives had presented various definitions and expectations for innovation. Multidisciplinary research, meant to settle the confusion, unveiled only parts of the whole picture, and in many cases, opened new questions. The difference in approaches limits the understanding of field-level processes and factors of innovation. Thus, measuring innovation and establishing a universal practice or method, to include all types of actors, industries, innovations, processes, etc. is extremely complicated (Kleinknecht and Bain 1993; Oslo Manual 2005). Regardless of the effort done, innovation still presents uncertainties. Attempts to capture innovation as a universal and very broad concept fail, often because of unsettled theoretical disputes, differences among theoretical and policy paradigms (Jessop 2008) or general limitation of the used methods. These missteps and obstacles are influencing gravely not only the academic success, in comprehending innovation, but also the practical implementation of public policies and most importantly the ability to formulate clear strategies and goals for national or supranational bodies.

Being a core economic imaginary for OECD and EU, the research on increasing innovative competences (through adequate assessment) in companies and regions will probably continue. That places special attention on the ways that innovation is measured, and what these practices can disclose about a better, more accurate conceptualization. Acknowledging the importance of innovation and the necessity to properly assess it, the paper aims to describe some of the best-known practices of innovation measurement and to deliberate on them, presenting several alternatives and their limitations. Such an exercise can help improve the actual understanding of the concept and visualize the evolution of variation, selection and retention mechanisms that innovation had been subjected to. And finally, it will present 
an interesting material for the engaged stakeholders in the public and private areas since the performed methodological review covers potential for research, policy and management practices. Thus, the paper is structured into five chapters, beginning with the introduction. The second part presents the knowing methodologies and the associated concepts, within a timely presentation of the practices of innovation measurement and brief deliberations about the specifications of these techniques. The third chapter is a presentation of measurement approaches, necessary for the adequate estimation of innovation, with some examples of measurements. Finally, paper covers the topic of management of innovation, followed by conclusions and discussions on the evolution of the measurements and potential for public policy.

\section{Proposed Methods to Measure Innovation}

Innovation is a complex concept and one that is hard to define. For example, it can be seen as either an idea (Bell 2005), a process (e.g. Guan and Chen 2010; Bloch 2007, McAdam and Keogh 2004) or defined as plain novelty (e.g. Oslo Manual 2005; Edison et all. 2013; Kleinknecht and Bain 1993). Moreover, it is considered a non-linear and sometimes random process that occurs at a path-dependent alignment of factors (Sanila 2017; Eddison et al. 2013; Erkens et al. 2013; Bloch 2007). The combination of these realities affects the quality of data, in the matter that it cannot be perfectly accessible, valid, reliable and transparent at the same time (Roncevic et al. 2017), which impede an accurate and unbiased assessment of innovation. But it does not imply that attempts lack a relative success.

The first endeavour to measure innovation was the tracking of patents and other related intellectual property (IP), such as trademarks, labels, trade journals etc. (Nelson et al. 2014; Kleinknecht and Bain 1993; Oslo Manual 2005). Patent-tracking is one of the most classical measurements of innovation because it can be seen as it's legal formalization. However, such an attempt holds several limitations. The risks are associated with the inability to cover all the occurred innovations since not all of the newly implemented changes are registered via a patent, trademark, or other IPs. The decision of patenting can be influenced by several factors like innovation's actual commercial usage, strategic value and firm's logistical need to patent, the status of innovation, industry-specific characteristics, etc. (Nelson et al. 2014; Kleinknecht and Bain 1993; Edison et al. 2013). These factors are responsible for the occurring errors in the measurement and can show a distorted picture in comparative perspectives. Nonetheless, patent tracking is still considered 
a valid method to quantify innovative performance, if used properly. There are several international organization that collect data about patents and other intellectual property rights issues, such as the World Intellectual Property Organization (WIPO) ${ }^{1}$. They have an open database allowing searches for registered patents trademarks, industrial designs, etc. based on their main field of application and country of origin. Another example can be "Derwent Innovation (Patent) Index"2, that is a database consisting of descriptions of inventions and patents since 1963. It resembles a conglomerate of patents from more than 50 patent-issuing authorities in the world and includes a brief description of the patent as well as indications of its patent family.

In the 1970s and 1980s, the effort to capture innovation engulfed more techniques. Aside from patent-searching, methods included tracking innovation in the historical relevant literature, expert consulting, postalsurvey etc. (Kleinknecht and Bain 1993). The last one showed significant results and grew momentum in various researches. From the 1990s, it is the main method of innovation measurement used by OECD.

Innovation Survey had become a common practice for quantifying novelty and originality in enterprises. Annually, organisations like Eurostat and OECD make available innovation-survey data. One of the most well-known, "Community Innovation Survey"3 (CIS), captures nationally aggregated data from different countries and measures different types of innovation and innovative activities. The questionnaire used by CIS is influenced by the OECD indications, written in the Oslo Manual (Kleinknecht and Bain 1993, Oslo Manual 2005). Manual covers the best-known practices of measuring innovation, meanwhile deliberating on factors jeopardizing the accuracy of results. Although surveys resemble a reliable methodology to capture innovation in companies and regional or national levels, they are limited to survey-related types of errors (Kleinknecht and Bain 1993). Such issues feature the low response rate, non-respondents' profiles, enterprise population, questionnaire length, etc. (Oslo Manual 2005). Even if it is considered one of the most consistent measurements, CIS and Oslo Manual had been widely criticised, because of the insufficient attention to non-

\footnotetext{
1 World Intellectual Property Organization https://www.wipo.int/portal/en/index.html. Accessed April 4, 2019.

2 Derwent World Innovation Index https://clarivate.libguides.com/webofscienceplatform/dii. Accessed April 4, 2019. ${ }^{3}$ Eurostat. CIS survey https://ec.europa.eu/eurostat/web/microdata/communityinnovation-survey. Accessed April 4, 2019.
} 
product or process innovations, innovations in services, management of innovation processes etc. (Bloch 2007; Damanpour 2014; Kleinknecht and Bain 1993). Nonetheless, surveys, especially CIS and OECD-related data, are suitable for the international comparison or even change-tracking. Its importance for innovation research should not be underestimated.

An important and valuable input for innovation understanding is perpetuated by the qualitative methods, usually case studies (e.g. Cooke 1992; Sohn and Kenney 2007). The most important aspect of case studies is the ability to formulate detailed conceptualization and observe the issues hidden from the survey perspectives. Many theories on innovation and examples that were suggesting these theories had been captured via observations and interviews. Nonetheless, being able to highlight the most important elements of macro and micro-level innovations for specific actors, case studies cannot formulate generalizations (Oslo Manual 2005). As opposed to survey's capabilities, to standardize the approach, qualitative methods are casespecific and were unable to satisfy all the public-policy decision-makers' needs. However, the inputs of case studies (firm and macro-level) are usually influencing the survey questionnaires and approaches, indicating that those can be used complementarily.

Acknowledging that nor qualitative nor quantitative methods are enough to properly answer all questions on innovation, researchers incorporate both methodological paradigms in their analysis. Such practices are usually done separately, with part of the data presented as survey databases or collected secondary data and another part being composed of contextual information and explanations for an accurate understanding of the trends. Combination of qualitative and quantitative information lead to opportunities of methodological focus in the field of mixed researches (e.g. Roncevic and Modic 2011; Roncevic et al. 2018; Cepoi 2018). One example of such methods consists of performing focus-groups and semi-structured interviews within regions, including respondents from academic, administrative and entrepreneurial sectors (Cepoi 2018). During the focus-group interviews, respondents are asked to agree upon a score (that describes a certain innovative characteristic or associated variable in their region), and deliberate it, so that the answer resembles a joint opinion of regional stakeholders. This approach allows for the collection of both qualitative data and quantitative estimates of innovativeness in regions or other macro-level units. This practice is especially useful for the assessment of socio-cultural factors, that usually are interconnected and multidimensional (Adam et al. 2005; Roncevic et al. 2017). Obtained scores can be used to perform a Qualitative Comparative Analysis (QCA), and QCA Fuzzy-set, or even a 
statistical "number crunching", if there are enough cases. The strength of such an approach lies in the ability to concentrate the expertise of various stakeholders, permitting a wider view on the innovation, and establishing a unique score that will resemble a more precise reckoning. However, it is not the best alternative to consider innovation on lower (micro-) levels, since surveys and direct interviews with firm representatives can achieve more accurate results. In its turn, the mixt methodology is also exposed to jeopardizing factors, such as respondents' inaccurate attitude or assumption errors. To mediate these factors, it might be useful to increase the numbers of focus groups in the same region, however, researchers admit that in practice, involving more stakeholders can resemble complications (Cepoi 2018). On the other hand, the field of mixed research is an adequate tool for confirmatory purposes (Roncevic et al. 2018) and has very limited explanatory potential, as it is mostly a tool for theory-testing rather than inductive analysis.

Innovation measurement methodologies usually come with certain types of errors (Oslo Manual 2005). In other words, surveys and interviews come with the risk of misinterpretation of concepts and are affected by the respondent's subjective judgement (Oslo Manual 2005; Kleinknecht and Bain 1993). On the other hand, patent-tracking is known to have limited results and sometimes to produce false-positives or false-negatives (Nelson et al. 2014). Thus, speciality literature suggests a mixed approach to cover for different factors (Rocha 2004; Guan and Chen 2010). The usefulness of any methodologies is primordially related to the research question so that it is up to the objective of the measurement to determine the most appropriate technique.

\section{Innovation Measurement Approaches}

When performing an investigation of any concept, there are usually several logical considerations and ways to address the issue. For example, the quality of any public policy will be assessed through the efficiency it dealt with the issue at hand and the time-cost-benefit ratio. A similar context is for innovation. Analysing scientific literature on the performed measurements, one might encounter the three main ways that innovation can be addressed. These are not mutually exclusive and can be integrated into the same methodological design. Approaches vary on the borders of conceptualization, quantification and interpretation of the unit of analysis, the interest in different stages of the innovative process, and the necessity to consider the 
types of innovations. These are not separate self-sufficient methodologies to analyse innovation but are components parts of such a methodology.

\subsection{The Subject-Object Approach}

The distinction between subject and object approaches (Oslo Manual 2005) refers to the attitude of treating enterprises (or other actors) and innovations as distinct units of analysis. In the Oslo Manual, those are presented from the enterprises' point of view. Thus, the subject approach refers to the innovative behaviour and practices of the company, as an analysed unit. The main goal is to explore the phenomenon of innovation from the perspective of the innovative actor, its strategies, activities, incentives, obstacles, aims and finally the effects and outcomes of innovation. Object approach is the collection of evidence about a specific innovation, involving all available qualitative and quantitative data, that usually includes information about the mother-enterprise. That description implies two conclusions. If the unit is the company, then measurement reflects its characteristics regarding innovative performance. That makes enterprises the subject of the research and innovation its object. If the unit is a certain innovation, then the company is treated as an object and researched as a tool for value creation. Although both approaches can collect similar information, the reasons differ, so would the conclusions of the analysis.

Regardless of the chosen unit, researchers can consider methods that engage or exclude it from the data collection. It refers to the need to involve and ask, for example, companies, about their innovative performance, or performing data collection without speaking to them. The first approach considers that actors have an educated understanding and assessment of the process and phenomenon of innovation. Such an approach is common for interviews and surveys (e.g. Oslo Manual 2005 and CIS; Kleinknecht and Bain 1993; Cepoi 2018). On the other hand, for patent-tracking or desktop research to assess companies' economic outcomes, the involvement of enterprises is not required, (e.g. some of the measurements of Yordanova and Blagoev 2016) since those data can be collected or are available through other various sources. Both practices are good countermeasures for certain types of measurement errors, however, they are not flawless themselves and shall be addressed as research questions demand it.

\subsection{Types of Innovations}

Oslo Manual (2005) covers another approach, regarding innovation measurement, and it is focused on differentiating between various type of possible innovations. The Oslo Manual defines four main classifications: 
Product, Process ${ }^{4}$, Organizational and Marketing Innovations. Delimiting those types of innovation had raised several questions (e.g. Manoochery 2010; Arundel and Huber 2013; Saulina 2016, 2017; Kleinknecht and Bain 1993; Dombrowski et al. 2013; Damanpour 2014). Most importantly, categorisation added new necessity for definitions, since it multiplied one undefined concept into four. The interpretation of these innovation types focuses on the element of novelty in product, production, management and marketing spheres. According to Oslo Manual (2005), the innovation, for each type, was seen as the integration of new procedures, practices, characteristics, etc. to the company's already existing experience. In other words, it counted as innovation any change that was performed for the first time by a company. In such a context, the definitions of innovative and non-innovative performances have a high risk to overlap. This is why Oslo Manual addresses the issue with caution and includes a set of distinctive characteristics, offering examples of non-innovations, for each innovation types. According to the Oslo Manual (2005):

\section{"Product Innovations exclude the following:}

- Minor changes and improvements;

- Routine upgrades;

- Regular seasonal changes (e.g. clothing lines);

- Customisation for a single client that does not include significant different attributes compared to products made for other clients;

- The simple resale of new goods and services purchased from other enterprises." (pp. 149-150).

\section{"Process Innovations exclude the following:}

- Minor changes or improvements.

- An increase in production or service capabilities through the addition of manufacturing or logistical systems which are very similar to those already in use." (pp.151)

\section{“Organisational Innovation excludes the following:}

- Changes in business practices, workplace organisation or external relations that are based on organisational methods already in use in the firm

\footnotetext{
${ }_{4}$ Refers to production processes, not innovation process.
} 
- Changes in management strategy, unless accompanied by the introduction of a new organisational method

- Mergers with, and the acquisition of other firms" (pp. 153)

\section{"Marketing innovations exclude the following:}

- Mergers with, and the acquisition of other firs promotion or pricing that is based on marketing methods that have previously been used by the enterprise.

- Seasonal, regular and other routine changes in marketing instruments

- The use of already applied marketing methods to target a new geographical market or a new market segment (e.g. socio-demographic group of clients)." (pp. 152)

The classification of innovation meant to deal with the banality of measurement and conceptualisation. However, it did not solve the problem entirely, since organisational and marketing innovations still suffer from a missing measurement system, and are mainly treated as dichotomous variables (Oslo Manual 2005; Saulina 2016, 2017; Kleinknecht and Bain 1993; Dombrowski et al. 2013; Damanpour 2014; Adams et al. 2006). Oslo Manual and CIS assess those via three questions: implementation of new incremental or radical changes to current business practices; application of new methods of work-organization and responsibilities; and establishment of new methods for managing new external relationships (Damanpour 2014). Even if some types of innovations are lacking consequent and quantitative measurements, dividing the concept into for types was an important first step, so that the focalisation of research and practices can be more concrete and accurate.

\subsection{Evaluation of Innovative Steps}

Regardless the unit of analysis and type of innovation, the conceptualisation of processes and quantification of data usually comes down to input, output, process or outcome measurements (Saunila 2017; Erkens et al. 2013). These are the integrative parts of innovation phenomenon, and a standard logicalchain of any process. As factors of innovation measurements, this approach encompasses the pre-innovation framework, the "black box" of the innovation process and ends in the resulting outcomes.

Inputs are usually understood as resources and tools, available and invested, in the innovation procedure (Saunila 2017; Erkens et al. 2013). Those can be material or immaterial and are dependent on the nature of innovation. Usually, input measurement includes human resources, financial 
investment, available capital, available equipment, and ideas (Saunila 2017). In practice one of the most prominent ways to measure inputs is to consider R\&D investment (Kleinknecht and Bain 1993; Oslo Manual 2005). However, not all the industries practice R\&D, and even in those that do, small and medium-sized companies (SME's) lack resources and capabilities for continuous research activities (Saunila 2016; Edison et al. 2013). Also, even in large industries, the innovation process is not limited to $R \& D$, because there are multiple other ways to gain required improvements (Kleinknecht and Bain 1993; Oslo Manual 2005). Such practices include quantification and analysis of: the number of new ideas presented by employees and ideas developed by R\&D department (but not yet implemented); the number of employees in $\mathrm{R} \& \mathrm{D}$, including their expertise and innovative capabilities; technical acquisitions; knowledge and IP rights acquisitions (e.g. licences, patents); expenditure for trainings, or other innovation expenditure identified by respondents (Kleinknecht and Bain 1993; Oslo Manual 2005; Saunila 2017; Yordanova and Balgoev 2016; 2014 CIS survey5). Innovation input is an important topic to cover, however, innovation is a non-linear phenomenon (Saunila 2017), and invested resources are not guaranteed to achieve a developmental break-through (Edison et al. 2013)

Moving from input measurements, the next stage is the innovative process. Speciality literature indicates that innovation process consists of all the parts that transform inputs into outputs of the innovation (Saunila 2017, Erkens et al. 2013). Simplest method to quantify this procedure is to assess: time/speed of innovation; costs and quality analysis; the processes of internal communication, dispersion of ideas, contacts, etc. (Saunila 2017; Adams et al. 2006); as well as the error ratio and budget variance (Erkens et al. 2013). A more demanding approach is to measure: effort related to the concept development; the use of available tools and opportunities provided by the organisation; assessment of needs and missing tools (BearingPoint 2011), etc. 2014 CIS survey and third edition of Oslo Manual (2005) cover other innovative processes like co-creation and external communication activities. Their emphasis is on the R\&D co-operations and co-creation activities with external organisations (Kleinknecht and Bain 1993), and the attention to the external links and communications, following open innovation practices (Vanhaverbeke and Brunswiker 2014). As McAdams and Keogh (2004) mentioned, innovation is a process without fixed stages. Thus, the

\footnotetext{
${ }^{5}$ Eurostat. CIS survey https://circabc.europa.eu/faces/jsp/extension/wai/navigation/container.jsp. Accessed April 4, 2019.
} 
conceptualisation of innovation process relies on both quantitative and qualitative measurements, to gain detailed insights on what caused innovation and how each factor had influenced the process. Due to the unpredictable nature of minor actions, sometimes, the persistence of a certain step or support factor can be crucial for innovation.

Third ones and the most frequently used, output and outcome, are preferable for most researchers or mangers because of their ability to adequately capture the end-results (Saunila 2017; Erkens et al. 2013). The output resembles innovation as a general concept since it deals with the result of the innovative process. The outcome is a longer-term benefit that tracks market-oriented performance (Erkens et al. 2013), and can include frequently monitored indicators used by companies. Literature stipulates that output measurement can include the number of new ideas, patents, registration of trademarks, publications and other IP implementation and development (Erkens et al. 2013; 2014 CIS survey). In terms of product and process measurement it can be assessed by counting new or significantly upgraded products; acquisition and selling of patented/registered technological and strategic knowledge; implementation of new processes, organizational characteristics or marketing strategies; the revenue from innovations selling; share of profit provided by the implementation of innovation; market success; customer satisfaction; etc. (2014 CIS survey; Oslo Manual 2005; Saunila 2017; BearingPoint 2011; Yordanova and Blagoev 2016).

The outcome measurements are different than input, process and output, by the fact that usually incorporate a comparison of two or more variables. It resembles the case of cost-benefit analysis and contrast variables against each other. The idea is to perform a critic relationship between inputs and outputs. Examples of outcome measurements can be the rate of sales, profit and number of customers related to the innovated goods/service against the success of the old ones; costs/efforts of implementation against the used resources in the process of concept development; rate of investment return from innovation-spent capital; market-share growth rate; feedback from customers; etc. (BearingPoint 2011). One may consider that outcome can resemble the comparison between the real efforts and the expectations, or the speed against schedule and/or the total duration of the project (Adams et al. 2006). Outcome measurement counts both qualitative and quantitative metric systems, including assessment of market benefits and those associated with other areas. It is reasonable to assume that innovation might be positively influencing company or region's reputation, network relationships, etc. so that outcome measurement can be expanded to a larger area, not only market profit. 
The indicators listed above are not the only possible alternatives to quantify innovative performance. Moreover, many of them can be used to measure different steps of innovation activity. For example, acquisition of foreign intellectual property can indicate an input for innovation, a step in the process of innovation as well as an innovation output. Such an example illustrates that measurement shall be contextualized and calibrated according to the needs of the research/management/policy (BearingPoint 2011; McAdam and Keogh 2004; Saunila 2016). McAdam and Keogh (2004) suggest that any innovation measurement, performed by a firm, shall be in line with the company's strategy and even be influenced by it. The purpose of each measurement shall be made explicit and be supported by comprehensive data-collection methods. Also, they stipulate that the definition and metrics shall be selected by all involved stakeholders and perform a degree of flexibility with organizational and environmental dynamics. In many ways, these suggestions are applicable also to macro-level innovators and can present opportunities for policy improvement.

\section{Management of Innovation}

Among the virtues that methods of innovation measurement have, there are also limitations for each quantification or evaluation procedure. R\&D activities are criticised to limit the respondent base, by being available for the companies that can pass a certain financial and organizational barrier to support a separate department's work. Revenue and financial metrics are seen as more related to company success rather than innovativeness, lacking knowledge about the transparency of innovative processes. Patents are hard to track and are subjects to definition errors. Surveys measurement are widely counting inputs and outputs factors that are related to innovation only indirectly, and many other factors that resemble limitations for the accurate innovation measurement (Edison et al. 2013; Saunila 2017; Oslo Manual 2005). All these limitations were a basic factor to grow new interest in alternative conceptualisation or quantification tools.

The continuous mechanism of variation, selection and retention of innovative imaginary had shifted again, but never deviated from the importance of innovation as a key semiotic for development. In that context, speciality literature had grown interested in the concept of management of innovation. This new semiotic interpretation is probably the first step of acknowledging a new innovative paradigm which considers that quantification of innovative factors and processes are not utterly capable to deliver enough and sufficiently accurate data about the exact innovative 
performance. Thus, some academic views focused on the ability of a company to achieve innovations continuously. That was addressed as innovation capability (Edison et al. 2013; Saunila 2016), innovation leadership (Yordanova and Blagoev 2016), or an internal organization of innovation (Vanhaverbeke and Brunswiker 2014).

Since inputs do not grant same innovation outputs in all the observed cases (Edison et al. 2013), researchers were interested in the factors that can predict the innovativeness and successful problem solving (Edison et al. 2013; Saunila 2016). The concept of innovation capability had been described as the combination/assessment of innovation inputs, positive influencing factors, availability and process synchronization (Edison et al. 2013). In other words, it is the analysis of determinants affecting enterprises' ability to perform innovations permanently (Saunila 2016). One can see that management innovation literature is preoccupied not by the outcomes of innovation but factors leading to it, and foster the idea of measurement and conservation of these elements. It mainly describes the process that can affect the probability of an enterprise to perform assimilation and integration of original new ideas into the old processes of production and organisation.

Company level innovation management is not related and affected only by the innovative inputs and outputs, but it combines them with routinisation and employee culture of delivering new innovative solutions. Bloch (2007) listed potential activities that can foster the developmental capacity of innovative actors, both atomized enterprises and Innovative Systems. Those are supposed to induce a pattern of behaviour and thinking, that can ensure a complex innovative atmosphere, or also mentioned as innovative routine (Saunila 2017) or innovative culture of enterprises (Edison et al. 2013). Firmlevel actions referred to R\&D efforts, network building and feedback gathering, development of new markets and competence building in the labour force. From the perspective of innovative systems, Bloch (2007) mentioned the necessity for support organisations, institutional management (regulations, lows), financial and administrative institution's integrity, growth of international competition and openness.

Regular outcome and output measurements can also help develop an innovative culture, by polishing the enterprise's innovation management and strategy (Edison et al. 2013). Periodic assessment of innovation performance helps establish links between actions and results, thus highlighting the innerfirm requirements for innovation. In this case, it is advised to consider a bottom-up strategy, that is resembling a day-to-day employee behaviour analysis (Edison et al. 2013). To be successful, such an approach shall focus on the most rewarding accomplishments and factors that made them possible 
(Saunila 2017). The problem to measure these success-determinants is their complexity and contextual character. That leads to the limited ability of conceptualisation, and usually, such concepts are captured via dichotomous variables, that are restraining analytical processes and offer substantial but very case-specific conclusions (Damanpour 2014).

Brunswicker and Vanhaverbeke (2014) proposed a model to measure innovation strategy processes, based on a list of seven binary variables. Those are: the ability of innovative actions to follow innovation strategy of the firm; ability to select clear targets for these strategies; strategies' capacity to affect each innovative project with individual manner; the degree of impact of strategic plans on the management visions; and the ability of innovation strategy to provide the basis for business growth and further innovativeness. Dombrowski et al. (2013) would add that whatever the indicators, they shall be able to transpose to different levels of hierarchical management and remain unchanged while capturing performance with the same accuracy. Also, the measurements have to ensure continuity and allow visualisation, so that the system of measurements can have its desired effect of enhancing innovative routine.

Many scholars indicated about the positive outcomes, by capturing attributes related to problem-solving and delivering of original ideas (Edison et al. 2013; Saunila 2016, 2017). Implementing such a system allows companies to comprehend the necessities and activities of their innovative performance. The same conclusion applies to academic and scientific efforts. Continuous and consistent measurement would only benefit the researchers to deal with the issue of uncertainty and inaccuracy. In this context, it is appropriate to say that one is not capable to master innovation if incapacitated to measure it (Erkens et al. 2013).

\section{Conclusions and Discussions}

Assessing innovative performance is a complicated task that struggles with the obstacles of an ambiguous definition of innovation, missing adequate performance measurement tools, and interpretation guidelines (Edison et al. 2013). Despite the crucial importance that innovation measurement has for the managerial and policy frames, it still resembles issues and lacks a concrete procedure. Academic society still does not have any universal methodological tool to capture innovation in a concrete and utterly unbiased way, engulfing all the possible and contextual matters. Presented examples of innovation measurement, either of product, process, management, marketing, input, output or outcome have limitations. Some may not be equivalently linked to 
the innovativeness as are related to the measurement of firm success, others are insufficient and firm-specific measurements that highly covariate with innovative actors' behaviour and beliefs. All the efforts made to quantify and express innovativeness had shown that it is not a simple variable to master. The process of deliberation on innovation data-collection and analysis, also the uncertainties related to innovation, had pushed the adoption of a different approach. It reflected in a new economic imaginary, stipulating actor's aptitude to innovate continuously, rather than performing the assessment of their ad-hoc success. Innovative capability, the concept attributed to that, still lacks a clear measurement strategy. However, it encourages innovative actors to perform periodic analyses of the processes and factors of innovation (Saunila 2016, 2017; Edison et al. 2013). This methodological model is still at its developmental stage and is an exercise to determine the most influential variables for the innovation process in enterprises, considering them as unique, atomized units (Yordanova and Blagoev 2016; Dombrowski et al. 2013).

Nonetheless, the effort so far had not been in vain. Many successful attempts, in both qualitative and quantitative research, had shown that certain aspects of the innovation can be generalized and enhanced. IPR tracking is still a very good way to consider the technical and legal aspects of innovations. Surveys are widely used for comparison and policy-adjustment. Also, research on innovation (e.g. case studies or mix methods) had unveiled multiple side-variables, linked to innovation (directly or indirectly) that are used today for performance monitoring, like Regional Innovation Scoreboard. Such practices show that despite the obstacles and issues, interest in innovation is still vivid and that finding an adequate assessment method is still actual. This also reinforces continuously the dialogue of innovation, performing a continuous revision and variance of the innovation economic imaginary.

In a timely perspective, innovation assessment had shown an interesting bipolarity, becoming more disintegrated from purely technological and economic aspects to more socio-cultural priorities, elaborated to comprehend it. Such changes are being correlated with the theoretical conceptualizations of innovation paradigms. In the early ' 90 s, the idea of innovation had spread from the individual performer to the group/community-driven models (e.g. Porter 1990; Cooke 1992; Cepoi 2018, etc.). These theories had embraced the idea that innovation can be achieved through socialization and collaboration, emphasizing the importance of knowledge exchange, spill-overs and similar practices of transfer of skill and information. That lead to the idea of innovation in groups - presented as regional/national innovations systems 
(Cooke 1992, Jessop 2008) or Social Fields Theory (Cepoi 2018; Rončević and Modic 2011; Modic and Roncevic 2018). These practices had greatly influenced policy agendas, since EU and OECD eagerly embraced the concepts, and through them readjusted their methodologies of innovation assessment (e.g. Oslo Manual 2005). Nowadays Europe 2020 strategy (2010) has embraced these visions and placed innovation at its core strategic vision of Knowledge-Based Economy. Example of Innovation Community Survey shows that the respondents are asked about their developmental performance, and alongside it, the ways they collaborate or achieve these innovations. The change in paradigm had caused a change in approach. Thus, the innovation is not seen as technical performance, as in patent tracking, but enterprises had been presented as experts of their innovation progress. Understanding innovation as contextual phenomena relates it to the attitude of the actors of innovation (Oslo Manual 2005). It includes a comparative judgement between old and new ways and engulfs changes that are completely or significantly new to a firm. In other words, innovation resembles everything that is used for the first time by a certain performer. Circumstantial definition leads to its subjective conceptualisation. It implies that the opinion of performers of innovation is the judgement-barrier, to attribute the status of the innovative or no-innovative result. Such an approach shares a resemblance with the assessment of cultural and social values. Although it might not be as volatile, innovation still can be seen as a cultural phenomenon (e.g. Cepoi 2018; Saunila 2016, 2017; Edison et al. 2013, Yordanova and Blagoev 2016). Such an example shows how the variation, selection and retention mechanism (Jessop and Oosterlynck 2008) had worked in the case of innovation. Although the concept (economic imaginary) stayed the same, its understanding, reflected through the methods and paradigms of its assessment, changed significantly. And, alongside them, there were different policies, actions and reactions intended to measure and manage innovation.

One important conclusion to draw from this, is that innovation seems to fit the description of what Jessop (2008) was addressing as "transdiscursive term" (quoted from Miettinen (2002)). Jessop (2008) attributes the term to the imaginary of National System of Innovation, however, the innovative discourse also seems to fit the description. In this regard, innovation as semiotic construct is capable to exist among and interconnect multiple social dialogues, including technical, economic, social and even cultural frames, and be successfully attached to real elements of this fields. This gives innovation the capacity to mobilize and support dialogues presented by various social strata under a common goal. And finally, innovation is constantly at the basis 
of creating new socio-cultural dialogues, including the Knowledge Society vision of Europe 2020. By considering these elements, it is not hard to realize why innovation is a such a strong semiotic imaginary with capacity to be the century's economic "flag-imaginary". Reinforced by the changes in the way innovation is being envisioned, the constant shifts towards idea that it is a socio-cultural phenomenon, adequate measurement of innovation remains a crucial necessity.

However, despite its value for cultural political economy, it is hard to say that innovation, as an economic imaginary, was promoted perfectly at EU level (Makarovic et al. 2014). General strategy of Europe 2020, elaborated at Lisbon is now considered a failure, because of its incompetence in the fields of retaining and reinforcing relevant dialogues and their routinization at multiple social and institutional levels (Makarovic et al. 2014). EU is promoting innovation, co-creation and collaboration through financed projects, but it can also do more in terms of micro- , meso- and macro-political dialogue. Presenting innovation as an issue of soft power, in terms of "we can learn from each other, to become better together" can give EU a perspective for capitalizing on innovation as a cultural value and distinctive portrayal of the Union. On the other hand, there is also a possibility to integrate the political discourse from the paradigm of Management of Innovation. Mastering the mechanism of variation, selection, retention, reinforcement and selective recruitment (Jessop and Oosterlynck 2008: 1159), EU could transpose the Management of Innovation as economic imaginary for regional and enterprise-level strategies. That can achieve a prominent impact on economic performance, if players in economic game would be self-aware of their requirement to innovate. By already being at the core of EU economic strategies, promoting innovation through soft-power discourses can resemble a good practice and help develop common visions. As time is moving towards 2020, and Union will face the need to consider its long-term strategies very soon, the dialogue on a common interest, like innovation, can help reduce the uncertainty and the accumulated anxiety from EU's identity crisis.

Despite multiple attempts to capture innovation and understand it (e.g. Oslo Manual 2005), an accurate answer is still missing. The fact that regions, nations and even bodies like OECD and EU are basing strategies and policies on the fragments of knowledge that they have about innovation is pressuring the issue. It is no longer, and probably never truly were, only an academic interest. More research is required and new attempts shall be made to settle the disputes and establish the importance of environmental factors that induce to innovative performance. 


\section{References}

Adam, F., Makarovic, M., Roncevic, B. and Tomsic, M. 2005. The Challenges of Sustained Development: The Role of Socio-cultural Factors in East-Central Europe. New York; Budapest: CEU Press.

Adams, R., Bessant, J., and Phelps, R. 2006. "Innovation Management Measurement - A Review." International Journal of Management Reviews 8 (1): 21-47. Doi: 10.1111/j.1468-2370.2006.00119.x.

Arundel, A., and Huber, D. 2013. "From too little to too much innovation? Issues in measuring innovation in the public sector." Structural Change and Economic Dynamics 27: 146-159. Doi: 10.1016/j.strueco.2013.06.009.

BearingPoint. 2011. Measuring Innovation: Sustaining competitive advantage by turning ideas into value. Bearing Point - Management \& Technology Consultants.

Bell. G. G. 2005. "Research Notes and Commentaries. Cluster, Networks and Firm Innovativeness." Strategic Management Journal 26: 287-295.

Bloch, C. 2007. "Assessing recent development in innovation measurement: The third edition of the Oslo Manual." Science and Public Policy 34 (1): 23-34. Doi: 10.3152/030234207X190487.

Brunswicker, S., \& Vanhaverbeke, W. 2015. “Open Innovation in Small and Medium-Sized Enterprises (SMEs): External Knowledge Sourcing Strategies and Internal Organizational Facilitators." Journal of Small Business Management 53 (4): 1241-1263. Doi: 10.1111/jsbm.12120.

Cepoi, V. 2018. Social networks as factors of innovation: Doctoral dissertation. FUDS, Novo gorica, Ljubljana.

Cooke, P. 1992. "Regional Innovation Systems: Competitive Regulation in the New Europe." Geoforum 23 (3): 365-382. Doi: 10.1016/00167185(92)90048-9.

Damanpour, F. 2014. "Footnotes to research on management innovation." Organization Studies 35 (9): 1265-1285.

Doi: $10.1177 / 0170840614539312$. 
Dombrowski, U., Schmidtchen, K., and Ebentreich, D. 2013. "Balanced Key Performance Indicators in Product Development." International Journal of Materials, Mechanics and Manufacturing 1 (1): 27-31.

Doi: 10.7763/IJMMM.2013.V1.6.

Edison, H., Bin Ali, N., and Torkar, R. 2013. "Towards innovation measurement in the software industry." Journal of Systems and Software 86 (5): 1390-1407. Doi: 10.1016/j.jss.2013.01.013.

Erkens, M., Wosch, S., Luttgens, D., and Piller, F. 2013. innovationmanagement.se http://www.innovationmanagement.se/2013/06/14/measuring-openinnovation-3-key-principles-to-improve-your-innovation-measurementpractices-part-1/.

Measuring Open. Innovation-3. Key Principles to Improve Your Innovation Measurement Pra, Part 1. Retrieved from http://www.innovationmanagement.se/2013/06/14/measuring-openinnovation-3-key-principles-to-improve-your-innovation.

European Commission. 2010. Europe 2020. A strategy for smart, sustainable and inclusive growth.

https://ec.europa.eu/eu2020/pdf/COMPLET\%20EN\%20BARROSO\%20\%2 0\%20007\%20-\%20Europe\%202020\%20-\%20EN\%20version.pdf.

Granovetter, M. 1985. "Economic Action and Social Structure: The Problem of Embeddedness." The Sociology of Economic Life 91 (3): 481-510.

Grant, K., Alefantos, T., Meyer, M., and Edgar, D. 1970. "Capturing and measuring technology based service innovation-A case analysis within theory and practice." International Journal of Information Management 33 (5): 899-905. Doi: 10.1016/j.ijinfomgt.2013.07.002.

Guan, J., and Chen, K. 2010: "Measuring the innovation production process: A cross-region empirical study of China's high-tech innovations." Technovation 30 (5-6): 348-358. Doi: 10.1016/j.technovation.2010.02.001.

Jessop, B. 2008. "A Cultural Political Economy of Competitiveness and its Implications for Higher Education." In Education and Knowledge Based Economy in Europe, pp. 13-40. 
Jessop, B., and Oosterlynck, S. 2008. "Cultural political economy: On making the cultural turn without falling into soft economic sociology." Geoforum 39 (3): 1155-1169. Doi: doi.org/10.1016/j.geoforum.2006.12.008.

Kleinknecht, A., and Bain, D. 1993. New Concepts in Innovation Output Measurement. Animal Genetics.

Makarovič, M., Šušteršič, J., and Rončević, B. 2014. "Is Europe 2020 Set to Fail? The Cultural Political Economy of the EU Grand Strategies." European Planning Studies 22 (3): 610-626.

Doi: 10.1080/09654313.2013.782387.

Manoochehri, G. 2010. "Measuring innovation: Challenges and best practices." California Journal of Operations Management 8 (1): 67-73. Retrieved from http://www.csupom.org/PUBLICATIONS/2010-1/2010-1-8.pdf.

McAdam, R., \& Keogh, W. 2004. "Transitioning Towards Creativity and Innovation Measurement in SMEs." Creativity and Innovation Management, 13 (2): 126-139. Doi: 10.1111/j.0963-1690.2004.00300.x.

Modic, D., and Roncevic, B. 2018. "Social Topography for Sustainable Innovation Policy: Putting Institutions, Social Networks and Cognitive Frames in Their Place." Comparative Sociology. Doi: 10.1163/15691330-12341452.

OECD, and Eurostat. 2005. Oslo Manual.

Doi: $10.1787 / 9789264013100-$ en.

Porter, M. 1990. “Competitive Advantage of Nations." Competitive Intelligence Review 1 (1): 14-14. Doi: 10.1002/cir.3880010112.

Rončević, B., and Modic, D. 2011. "Regionalni sustavi inovacija kao društvena polja." Sociologija i Prostor, 313-333. Doi: 10.5673/sip.49.3.3.

Rončević, B., Makarovič, M., Tomšič, M., and Cepoi, V. 2017. "Methodological solutions for comparative research on transformations." In The Routledge International Handbook of European Social Transformations, pp. 57-70. Doi: 10.4324/9781315612942.

Rosemberg, N. 2004. Innovation and Economic Growth. OECD paper. 
Saunila, M. 2016. "Performance measurement approach for innovation capability in SMEs." International Journal of Productivity and Performance Management 65 (2). Doi: 10.1108/02656710210415703.

Saunila, M. 2017. "Understanding innovation performance measurement in SMEs." Measuring Business Excellence 21 (1): 1-16.

Doi: 10.1108/MBE-01-2016-0005.

Sohn, D. W., and Kenney, M. 2007. "Universities, Clusters, and Innovation Systems: The Case of Seoul, Korea.” World Development 35 (6): 991-1004. Doi: 10.1016/j.worlddev.2006.05.008.

Zornitsa Yordanova, D. B. 2016. "Measuring the Bulgarian IT Sector Innovations Capabilities Through Company Innovative Leadership Model." Economic Alternatives 3: 379-393. 